\title{
Social factors associated with pulmonary hydatid cyst in Aegean, Turkey
}

\author{
Sanli $\mathrm{A}^{1}$, Onen $\mathrm{A}^{1}$, ${ }^{*}$ Karapolat $\mathrm{S}^{2}$, Atinkaya $\mathrm{C}^{3}$, Yuncu $\mathrm{G}^{3}$, Eyuboglu GM${ }^{1}$, Cankurtaran $\mathrm{Y}^{4}$, Ozdemir $\mathrm{N}^{1}$ \\ 1. Department of Thoracic Surgery, Faculty of Medicine, Dokuz Eylul University, Izmir, Turkey \\ 2. Department of Thoracic Surgery, Faculty of Medicine, Duzce University, Duzce, Turkey \\ 3. Department of Thoracic Surgery, Faculty of Medicine, Pamukkale University, Denizli, Turkey \\ 4. Research student, Faculty of Medicine, Dokuz Eylul University, Izmir, Turkey
}

\begin{abstract}
Background: Pulmonary hydatid cysts are caused by larval forms of the tapeworm Echinococcus granulosus. Hydatid disease, which is endemic in Turkey, is an important health problem in agricultural and stockbreeding areas where there are insufficient environmental health and preventive medicine services. Previous studies on this topic reported that hydatid disease was frequently associated with stockbreeding in rural areas.

Objectives: In this retrospective clinical study, it is aimed to evaluate the social factors associated with pulmonary hydatid cyst in the Aegean region of Turkey.

Methods: Seventy-one pulmonary hydatid cyst cases reported between 1998 and 2010 in four hospitals in the Aegean region for which data were available on social and lifestyle factors were reviewed.

Results: In contrast to expectations, we found that pulmonary hydatid disease in the Aegean region was associated with city rather than rural life and with occupations other than stockbreeding.

Conclusion: The findings are attributed to the presence of uncontrolled dogs in the city and urban environmental pollution. The offices of the public administration have a responsibility to inform citizens about the control of street animals, environmental health, and food hygiene.
\end{abstract}

Keywords: Echinococcosis, Pulmonary; Environmental Pollution; Public Health Practice; Social Protection; Thoracic Surgery African Health Sciences 2011; 11(S1): S82 - S85

\section{Introduction}

Hydatid cysts are found mainly in the liver and lungs. Metacestode forms of E. granulosus cause pulmonary hydatid cyst. The life cycle of the parasite requires definitive host carnivores such as the dog, coyote, or wolf-and intermediary host-herbivores such as sheep, goat, camel, cattle and omnivores such as swine and humans ${ }^{1}$. In humans, echinococcosis is endemic in countries where sheep breeding is common, and where there is close contact with $\operatorname{dogs}{ }^{2}$.

The prevalence of the disease worldwide is $1-500 / 100,000$ individuals and the incidence is $5-$ $20 / 100,000$. In Turkey, the prevalence is $0.87-6.6 /$

\footnotetext{
*Corresponding author

Sami Karapolat

Department of Thoracic Surgery

Faculty of Medicine, Duzce University

Duzce, Turkey

Menderes Cadd, No: 52 / 8

Buca, Izmir, Turkey

Phone: (+90 232) 4266989

E-mail: samikarapolat@yahoo.com
}

100,000 and the incidence is $3.4 / 100,000^{3-7}$. The disease occurs in almost all regions of our country but is most common in Eastern, South eastern and Central Anatolia ${ }^{8}$. According to previous studies, there were 21,303 cases of hydatid disease recorded between 1987 and 19943, 5 .

The high prevalence of the infection is related to an abundance of sheep-goat herds, large numbers of dogs without antiparasitic treatment and general unhygienic conditions in the workplace, home, and environment. E. granulosus is more common than $E$. multilocularis due to the availability of various hosts ${ }^{5}$, 7.

Additional factors associated with the prevalence of hydatid disease in Turkey are the country's zoogeographical structure, climate conditions, social and economic conditions, poor veterinary health, and lack of public education about E. Granulosus prevention.

Most previous studies of pulmonary hydatid disease were conducted in rural areas of Eastern and South- 
eastern Anatolia where stockbreeding is common. Evaluation of the prevalence of pulmonary hydatid cysts in the Aegean region will yield information on the disease in a developed area where socioeconomic conditions are different from those elsewhere in the country.

\section{Methods}

Seventy-one patients with pulmonary hydatid cysts who underwent surgery at the Thoracic Surgery Clinics of Izmir Bozyaka SSK, Izmir Alsancak State Hospital, Izmir Dokuz Eylul University Hospital, and Denizli Pamukkale University Hospital between 1998 and 2010 were retrospectively reviewed. Distribution according to age and sex is shown in Table 1.

The diagnosis of hydatid cyst was based on the results of chest radiography, computerised thorax tomography, and abdominal ultrasound. Routine complete blood and complete urine counts were obtained preoperatively and indirect haemaglutination tests were conducted in cases of suspected disease.

\section{Table 1: Age and sex distribution of cases}

\begin{tabular}{lll}
\hline Age & Female & Male \\
\hline $10-20$ & $3(4.2 \%)$ & $4(5.6 \%)$ \\
$21-30$ & $9(12.7 \%)$ & $5(7.0 \%)$ \\
$31-40$ & $7(9.8 \%)$ & $5(7.0 \%)$ \\
$41-50$ & $7(9.8 \%)$ & $8(11.2 \%)$ \\
$51-60$ & $9(12.7 \%)$ & $5(7.0 \%)$ \\
$61-70$ & $3(4.2 \%)$ & $4(5.6 \%)$ \\
$71-80$ & 0 & $1(1.4 \%)$ \\
$80+$ & 0 & $1(1.4 \%)$ \\
Total & $38(53.5 \%)$ & $33(46.5 \%)$ \\
\hline
\end{tabular}

\section{Results}

The localization of the cysts is shown in Table 2. In addition to pulmonary hydatid cysts, cysts were also present in the liver (13), kidney (1), and gall bladder (1). Eighty surgical procedures were performed in 71 cases as shown in Table 3. Postoperative atelectasis developed in $7(9.8 \%)$ cases, reoperation was required in 1 case $(1.4 \%)$ due to an extended air leak, and empyema occurred in 4 cases $(5.6 \%)$. One $(1.4 \%)$ individual died due to respiratory failure. Socioeconomic and lifestyle characteristics of the cases are also presented in table 4 .
Table 2: Localisation of cysts

\begin{tabular}{ll}
\hline Right Lung & \\
\hline Upper Lobe & 12 \\
Middle Lobe & 10 \\
Lower Lobe & 36 \\
Total & $\mathbf{5 8}$ \\
Left Lung & \\
Upper Lobe & 9 \\
Lower Lobe & 13 \\
Total & $\mathbf{2 2}$ \\
\hline
\end{tabular}

Table 3: Surgical intervention types

\begin{tabular}{lcc}
\hline Surgical intervention & n (\%) \\
\hline Cystotomy-Capitonage & $37(46.2 \%)$ \\
Cystectomy-Enucleation & 20 & $(25 \%)$ \\
Right lung and transdiaphragmatic & liver cyst \\
intervention at same session & 6 & $(7.5 \%)$ \\
Cystotomy & 6 & $(7.5 \%)$ \\
Segmentectomy & 6 & $(7.5 \%)$ \\
Lobectomy & 5 & $(6.2 \%)$ \\
\hline
\end{tabular}

Table 4: Socio-economic and lifestyle factors associated with hydatid cysts

\begin{tabular}{ll}
\hline Variable & $\mathbf{n} \mathbf{( \% )}$ \\
\hline City centres & $37(52.1 \%)$ \\
Counties & $22(31 \%)$ \\
Towns & $1(1.4 \%)$ \\
Villages & $11(15.5 \%)$ \\
Stockbreeder & $14(19.7 \%)$ \\
Farmer & $7(9.8 \%)$ \\
Other occupation & $50(70.4 \%)$ \\
Use of city water & $43(60.5 \%)$ \\
Use of well water & $7(9.8 \%)$ \\
Use of bottled water & $21(29.5 \%)$ \\
With sewage system & $59(83.0 \%)$ \\
Without sewage system & $12(16.9 \%)$ \\
With family history & $16(22.5 \%)$ \\
Without family history & $55(77.4 \%)$ \\
With recurrence & $12(16.9 \%)$ \\
Without recurrence & $59(83.0 \%)$ \\
Food washing-good & $52(73.2 \%)$ \\
Food washing-poor & $19(26.7 \%)$ \\
\hline
\end{tabular}

\section{Discussion}

Although pulmonary hydatid disease is reported across all age groups, it principally affects adults. In previous studies, the majority of cases of hydatid cysts were reported in individuals aged 15-35 years, although the ages of those affected varied between 
3 and 70 years ${ }^{1,5}, 9$. In our study, the disease was common in individuals aged 21 - 30 years and 51 60 years.

Studies also reported that more women than men were infected with the disease $\mathrm{e}^{10-14}$. The sex difference has been attributed to women being more responsible for animal care and food preparation in the home. Some regional studies, however, found no such relationship, a finding attributed to both men and women being involved in stockbreeding ${ }^{15}$. In our study, pulmonary hydatid cysts occurred in 53.5\% of women and $46.5 \%$ of men. This finding can also be explained by women having more responsibility for food preparation at home and the care of domestic animals. This study also, it showed that most women did not pay sufficient attention to hygienic conditions prior to being diagnosed with hydatid disease, but they cared more about food hygiene subsequent to the diagnosis.

Although stockbreeding is less common in Aegean regions compared to the eastern part of the country, the rate of hydatid disease increases as a result of farming and consumption of vegetables and fruits ${ }^{13}$.

According to our study, hydatid disease mainly affected individuals who live in city centres with access to mains sewage systems and chlorinated water: - they are not involved in farming or stockbreeding. This paradoxical finding requires a review of the correlation between the disease and human, environmental, and social conditions.

In reference to the findings the following issues were summarised:

Modernisation of village life, including the improvement of agricultural and breeding conditions, health protection, and the development of a sewage infrastructure has led to a decrease in cases of hydatid disease in rural areas;

There are conclusions to be drawn from the fact that most cases occurred in the city centres;

The increase in the number of cases associated with the municipal water supply is significant. Since questions were raised about the safety of the city water supply, $30 \%$ of cases in the study consumed bottled water. They drink the water, and use it also in food preparation. The hygiene and safety of the water should be questioned;

Since individual understanding of hygiene is variable, appropriate cleaning of fruits and vegetables might differ. Only $10 \%$ of cases were associated with use of well water;
The absence of a family history of hydatid disease in the affected cases may be explained by the disease being associated mainly with food purchased in public places rather than with family hygiene;

The most important issue associated with the prevalence of hydatid disease in the city is the abundance of stray dogs compared to rural areas. These animals spread the disease, and therefore, pose a greater risk than domestic cats and dogs or stockbreeding.

\section{Conclusion}

Pulmonary hydatid disease spreads as a result of contamination by abundant stray dogs and consumption of foods without proper cleaning. Therefore, public administration officers, city councils, and health corporations should take steps to control street animals and improve food hygiene and environmental health.

\section{References}

1. Onen A, Sanlý A, Avcý BY. Giant Hydatid Cyst of the Lung: Presentation of 10 Cases. Journal of Thorax 2004;5: 106-9.

2. Gormus N, Durgut K, Ozergin U et al. Suppurated mediastinal and cardiac echinococcosis: report of a case. Surg Today 2005;35: 668-70.

3. Merdivenci A, Aydinlioglu K. Hydatidosis. Istanbul University, Publications of Medical Faculty 1982.

4. Kokturk O, Guruz Y, Akay H et al. Parasitic Lung Diseases, The Guide Book of Diagnosis and Treatment. Journal of Thorax 2002;3: 1-16.

5. Merdivenci A. Hydatid Disease on Turkey. Cerrahpasa University, Publications of Medical Faculty 1976.

6. Doganay A, Kara M. Epidemiology and prophylaxis of Echinococcosis in Turkey and around the world in terms of animal health. Journal of Surgery (Clinics of Turkey) 1998;3: 17181.

7. Schantz PM, Rausch RL. Hydatid Disease (Echinococcosis) Public Health and Preventive Medicine. $14^{\text {th }}$ edn. Maxcy-Rosenau-Lost. Wallace Robert-Standford-Connecticut. 1999.

8. Altintas N, Yazar S, Yolasigmaz A et al. The detected cases of Alveolar Echinococcosis in Turkey between the years 1980-1998. Türkiye Parazitol Derg. 1999;23: 133-6. 
9. Ammann RW, Eckert J. Cestodes. Echinococcus. Gastroenterol Clin North Am 1996;25: 655-89.

10. Aldemir OS, Baykan M, Gokcen A. The retrospective evaluation of patients with cystic echinococcosis between the years 1986 to 1998 on Konya Numune Hospital. Türkiye Parazitol Derg. 2000;24: 73-5.

11. Aslan G, Aslan B. Echinococcosis on the region of Sanliurfa. Türkiye Parazitol Derg. 2001;25: 145-7.

12. Asci Z, Seyrek A, Kizirgil A et al. Prevalence of Echinococcus granulosus in Elazig Region as Detected by Casonie test. Türkiye Parazitol Derg. 1997;21: 257-9.
13. Ertabaklar H, Pektas B, Turgay N et al. The detected patients with cystic echinococcosis between the years January 1997-May 2001 on the hospitals in Izmir and around. Türkiye Parazitol Derg. 2003;27: 125-8.

14. Inceboz $\mathrm{T}$, Uner $\mathrm{A}$. The detected patients with unilocular cystic echinococcosis on Manisa State Hospital. Türkiye Parazitol Derg. 2000;24: 29-32.

15. Karaman U, Miman O, Kara M et al. Hydatid Cyst Prevalence in the Region of Kars. Türkije Parazitoloji Derg. 2005;29: 238-40. 